\title{
Theoretical Study on Tuning Band Gap and Electronic Properties of Atomically Thin Nanostructured $\mathrm{MoS}_{2} /$ Metal Cluster Heterostructures \\ Saju Joseph, ${ }^{\dagger}, *$ Simil Thomas, ${ }^{*}$ Jainy Mohan, ${ }^{\dagger}$ Anusha Saji Kumar,${ }^{\S}$ Sruthi Thulaseedharan Jayasree, ${ }^{\S}$ Sabu Thomas, ${ }^{\dagger, \ddagger}$ and Nandakumar Kalarikkal ${ }^{\dagger, \S, *}$ \\ ${ }^{\dagger}$ International and Inter University Centre for Nanoscience and Nanotechnology, Mahatma Gandhi University, Kottayam, 686560, Kerala, India \#Department of Physics, Government College Nedumangad, Trivandrum, 695541, Kerala, India
}

${ }^{\S}$ School of Pure and Applied Physics, Mahatma Gandhi University, Kottayam, 686560, Kerala, India

${ }^{\ddagger}$ School of Chemical Sciences, Mahatma Gandhi University, Kottayam, 686560, Kerala, India 


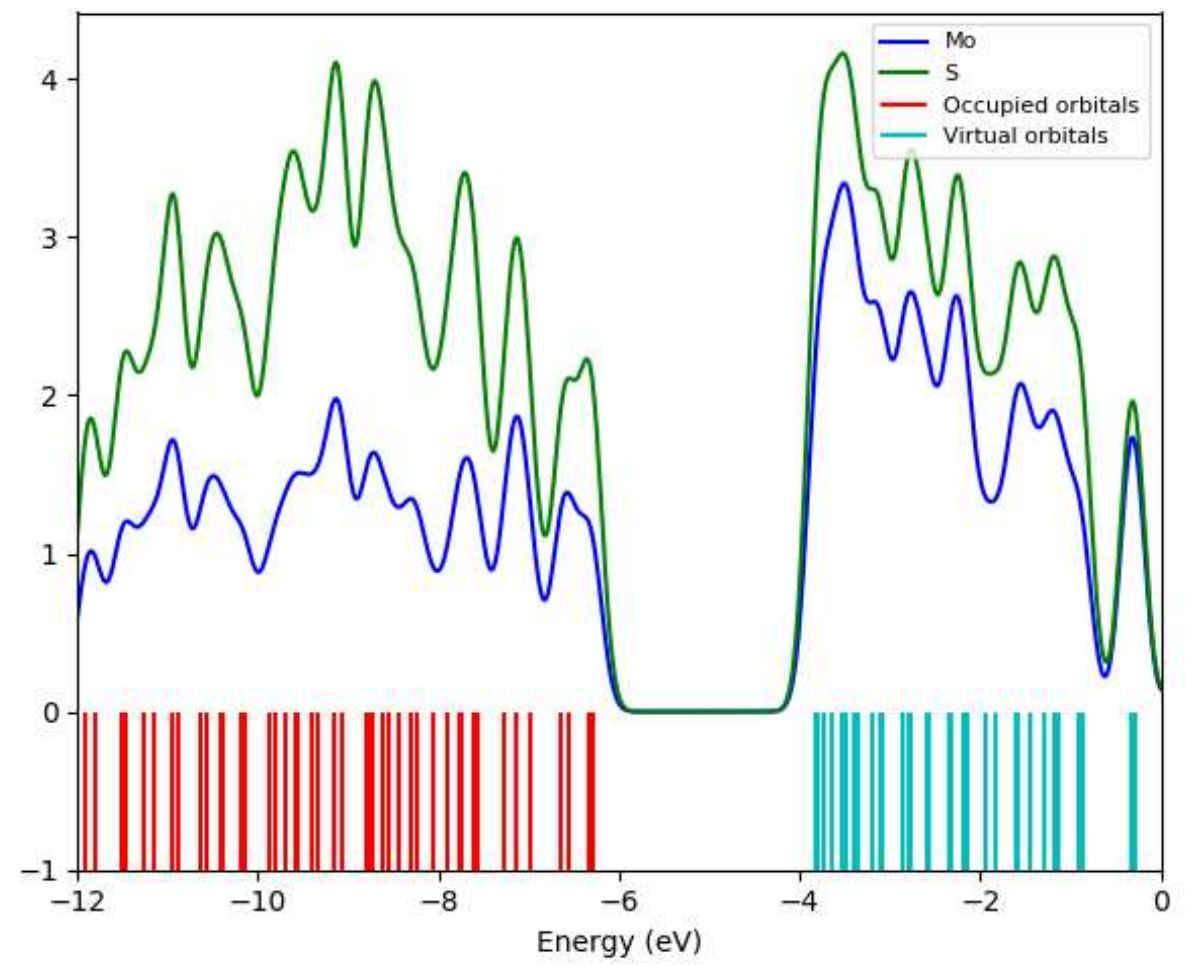

Figure 1: Density of states (DOS) of $\mathrm{MoS}_{2}$. 


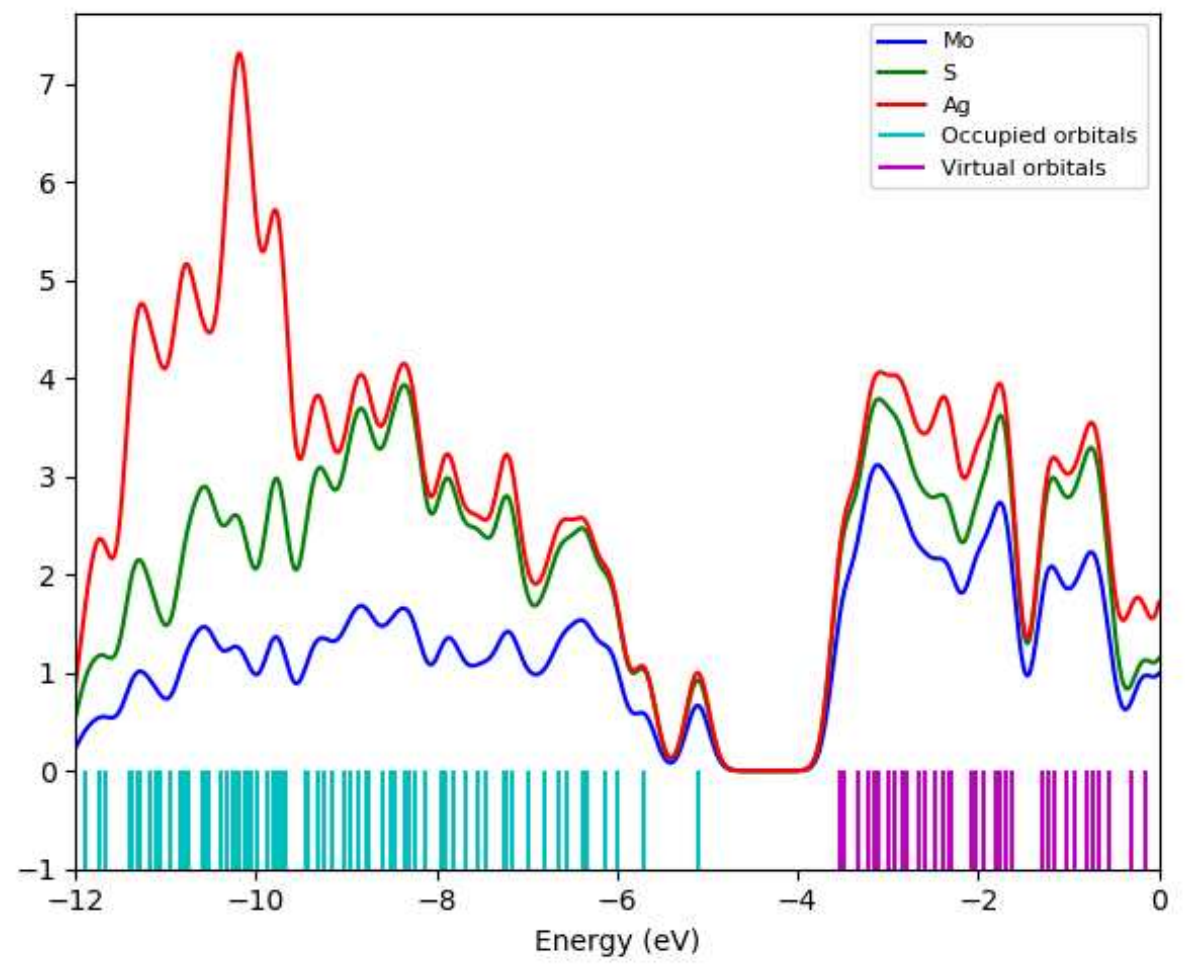

Figure 2: Density of states (DOS) of Silver $/ \mathrm{MoS}_{2}$. 


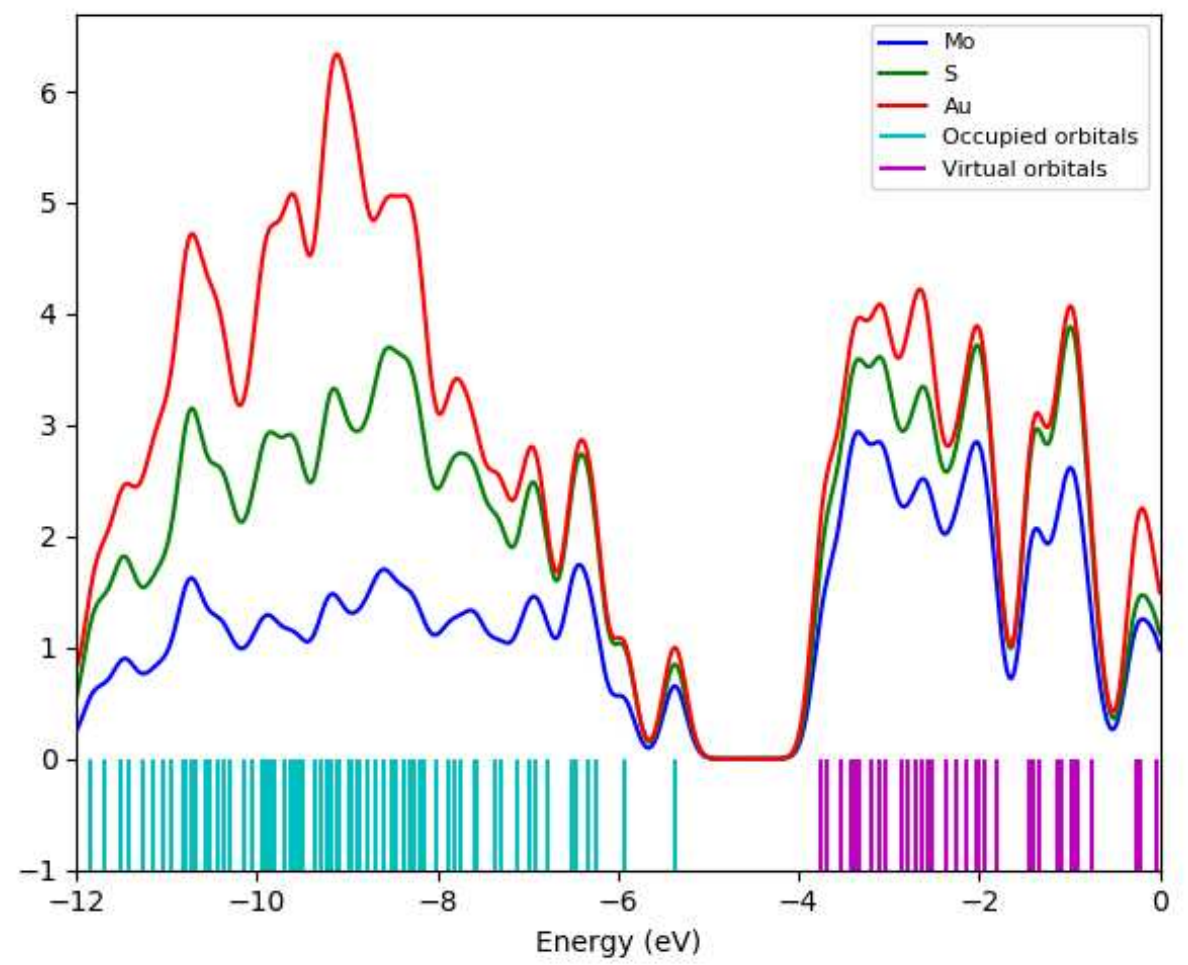

Figure 3: Density of states (DOS) of Gold/MoS 2 . 